\title{
RESPONSABILIDAD DEL ESTADO POR HECHO \\ INTERNACIONALMENTE ILÍCITO DEL ESTADO. ¿MÁS DE 40 \\ AÑOS DE LABOR DE LA COMISIÓN DE DERECHO INTERNACIONAL PARA NADA?
}

\begin{abstract}
Roxana de Jesús ÁvAlos VÁZQUEZ*
RESUMEN: La responsabilidad internacional del Estado es uno de los asuntos más controvertidos con los que se ha tenido que enfrentar la Comisión de Derecho Internacional, desde que el mismo fue propuesto por la Asamblea General en 1953. Tema que ha conocido la labor de cinco relatores especiales y más de 40 años de trabajo. El presente artículo tiene por objeto hacer algunas anotaciones acerca de alguno de los puntos controvertidos contenidos en el proyecto de artículos aprobado por la Comisión de Derecho Internacional en segunda lectura en 2001, tales como el daño, las consecuencias de violaciones graves de obligaciones emanadas de normas imperativas de derecho internacional general, así como los artículos relativos a la invocación de la responsabilidad.

ABSTRACT: The question about State Responsibility is one of the controversial subjects that the Commission of International Law dealt with since the same was proposed by the General Assembly in 1953. Subject that was worked by five Special Rapporteur. This article discusses the Draft Articles, adopted by the Commission in second reading in 2001, such as the injury, and consequences of serious breaches of obligations to the international community as a whole, and the invocation of the responsibility of a State.

RÈSUMÈ: La question de la Responsabilité des États est un des sujets les plus controversés que la Commission de Droit International ait traité, depuis que celui-ci a été proposé par l'Assemblée Générale en 1953. Cet article a pour objectif de faire quelques remarques au sujet de plusieurs aspects du Projet d'articles, approuvé par la Commission de Droit International en deuxième lecture en 2001. Cet article aborde entre autres le préjudice, les violations graves d'obligations dues à la communauté internationale dans son ensemble, ainsi que la question du droit pour un État d'invoquer la responsabilité d'un autre État.
\end{abstract} Américas.

* Doctora en derecho internacional y profesora de tiempo completo en la Universidad de las Anuario Mexicano de Derecho Internacional, vol. VI, 2006, pp. $579-598$ 
SUMARIO: I. Introducción. II. El proyecto sobre la responsabilidad del Estado por hechos internacionalmente ilícitos. III. Los artículos objeto de debate. IV. Conclusiones. V. Bibliografia.

\section{INTRODUCCIÓN}

Hace más de cuarenta años dio inicio, a petición de la Asamblea General de Naciones Unidas en 1953, la labor de la Comisión de Derecho Internacional sobre uno de los temas esenciales y espinosos del derecho internacional, la responsabilidad del Estado. En ese periodo se aprobaron otros trabajos de la comisión, ${ }^{1}$ muchos de los cuales se transformaron en convenciones firmadas y ratificadas por los Estados que pasaron a formar parte del sinnúmero de normas del derecho internacional vigente; sin embargo, el relativo a la responsabilidad fue aprobado en proyecto hasta 2001, en que se dio por enterada la Sexta Comisión de la Asamblea General sobre el mismo. ${ }^{2}$

El tema, difícil por naturaleza, conoció el enfoque y el trabajo de cinco relatores especiales, ${ }^{3}$ entre los cuales destacó la labor del gran jurista italiano Roberto Ago, quien imprimió en el proyecto una marcada diferencia con la concepción de Dionisio Anzilotti, ${ }^{4}$ sobre una responsabilidad netamente bilateral, al introducir no sólo el concepto de normas

1 Con justa razón, David Bederman explica que incluyendo la entrada en vigor de la Corte Penal Internacional, los siete pilares de la codificación jurídica internacional ha sido completada gracias en parte al trabajo de la Comisión de Derecho Internacional, inmunidades diplomáticas, derecho del mar, el derecho de los tratados, los Principios de Nüremberg, y la inmunidad de jurisdicción de los Estados. Bederman, David J. "Counterintuiting Countermeasures", American Journal of International Law, Washington, vol. 96, núm. 4, October 2002, p. 817.

2 En el documento A/59/505 7 del 7 de diciembre de 2004, quincuagésimo noveno periodo de sesiones de la Asamblea General, la sexta comisión propuso que el tema se ventilara en el sexagésimo segundo periodo de sesiones, y se solicitara a los gobiernos a presentar observaciones y su práctica al respecto, así como, la petición al secretario general para preparar una compilación inicial de las decisiones de los tribunales internacionales.

3 En 1955 se designó a F. V. García Amador como relator especial del tema, a quien sucedió Roberto Ago en 1963, Willem Riphagen en 1979, Gaetano Arangio Ruiz en 1987 y James Crawford en 1997.

4 Nolte, George, "From Dionisio Anzilotti to Roberto Ago: The Classical International Law of State Responsibility and the Traditional Primacy of a Bilateral Conception of Inter-state Relations", European Journal of International Law, núm. 13, 2002, pp. 1083 y ss. Spinedi, Marina, "From one Codification to another: Bilateralism and Multilateralism in the Genesis of the Codification of the Law of Treaties and the Law of State Responsibility", European Journal of International Law, núm. 13, 2002, pp. 1099 y ss. 
primarias y secundarias 5 en el derecho internacional, sino al determinar la distinción en el contenido de las obligaciones al incluir la figura del crimen internacional como una forma de responsabilidad agravada que atañe a la comunidad internacional en su conjunto conocer.

Este ha sido el escollo con el que se toparon los subsiguientes relatores especiales, al tener que trabajar sobre un enfoque que fue aprobado en primera lectura por la Comisión de Derecho Internacional en 1981, con el que no estaban del todo convencidos, y que generó un amplio debate entre los Estados y la doctrina internacional, no sólo por el aspecto de "penalizar" la responsabilidad, sino cuál sería el órgano u órganos encargados de su ejecución.

No obstante lo anterior, correspondió al australiano James Crawford, como relator especial, concluir con el proyecto y lograr la aprobación de la Comisión de Derecho Internacional en segunda lectura, para posteriormente entregarlo en manos de la sexta comisión, tratando de buscar un punto intermedio, al borrar el famoso artículo 19 de los crímenes internacionales y establecer el artículo 40 que regula las violaciones graves de obligaciones derivadas de normas imperativas de derecho internacional general, haciendo partícipe a la "comunidad internacional en su conjunto" de la obligación de hacer respetar una especie de orden público internacional; así como el establecimiento de contramedidas como forma de hacer cumplir al estado infractor sus obligaciones, entre otras aportaciones.

Después de revisar los múltiples informes de la Comisión de Derecho Internacional y de sus relatores especiales, de leer los debates de alto nivel entre sus miembros, todos prestigiados internacionalistas, quizás podremos no estar de acuerdo con algunas de sus opiniones o enfoques, pero definitivamente merecen nuestro respeto, porque desde su trinchera abordaron el tema con singular coraje haciendo gala de una gran erudición.

Ahora bien, cabe preguntarse si el proyecto en cuestión contiene una adecuada codificación del derecho de la responsabilidad internacional y hasta qué grado abarca disposiciones de desarrollo progresivo, situación en la que tanto la doctrina como los Estados no coinciden en aprobar. De ahí que es pertinente plantear las siguientes interrogantes:

5 No cabe duda la notoria influencia de H. L. A. Hart en su obra The Concept of Law, 2a. ed., Great Britain, Clarendon Press-Oxford, 1997, pp. 79 y ss. 
- ¿Por qué dicho proyecto ha sido tan duramente criticado no sólo por la doctrina internacional sino, principalmente, por los propios Estados?

- ¿Realmente ha sido adecuada la codificación del derecho de la responsabilidad internacional del Estado?

- ¿Las disposiciones de derecho progresivo contenidas en él lo benefician o perjudican?

- ¿Qué tan realista es el proyecto?

- ¿Podrá transformarse en un tratado multilateral que llegue a entrar en vigor?

Este documento va enfocado a tratar de contestar los cuestionamientos señalados previamente.

A efecto de lo anterior, en primer lugar haremos una breve descripción del proyecto, posteriormente, nos enfocaremos a los puntos controvertidos del mismo, para luego señalar sus ventajas y desventajas, y finalmente hacer un balance que nos permita considerar la posibilidad de su futura entrada en vigor al transformarse en cualesquier tipo de fuente del derecho internacional.

\section{EL PROYECTO SOBRE LA RESPONSABILIDAD DEL ESTADO POR HECHOS INTERNACIONALMENTE ILÍCITOS}

En la octogésima quinta sesión plenaria de la Asamblea General de Naciones Unidas, del 12 de diciembre de 2001, a través de la resolución $\mathrm{A} / \mathrm{RES} / 56 / 83$, dicho órgano tomó nota de la conclusión del trabajo de la Comisión de Derecho Internacional respecto del tema Responsabilidad del Estado por hechos internacionalmente ilícitos" y decidió incluirlo en el programa provisional de su 59o. periodo de sesiones.

El proyecto consta de 59 artículos y está dividido en cuatro partes:

- La primera refiere "El hecho internacionalmente ilícito del Estado", que comprende los capítulos relacionados con los principios generales, a la atribución de un comportamiento al Estado, la violación de una obligación internacional, la responsabilidad del Estado en relación con el hecho de otro Estado y las circunstancias que excluyen la ilicitud. 
- La segunda parte "Contenido de la responsabilidad internacional del Estado", consta de tres capítulos: el de principios generales, el relativo a la reparación del perjuicio, así como el de las violaciones graves de obligaciones emanadas de normas imperativas de derecho internacional general.

- La tercera parte denominada "Modos de hacer efectiva la responsabilidad internacional del Estado", se divide en dos capítulos: el de invocación de la responsabilidad del Estado y el de las contramedidas.

- Finalmente, la cuarta parte es el de las disposiciones generales.

Los tres primeros preceptos del proyecto establecen que el hecho internacionalmente ilícito del Estado genera su responsabilidad, calificación que se hace de conformidad con el derecho internacional, independientemente de que para el derecho interno no exista ilicitud.

El artículo 2 específicamente, determina los elementos del hecho ilícito, a saber: un comportamiento del Estado por acción u omisión atribuible al Estado y que constituya una violación de una obligación internacional del mismo. Es de observarse que en este precepto no se contempla la figura del daño como elemento sustancial del hecho ilícito, lo que analizaremos en el apartado siguiente.

Al regular el elemento subjetivo del hecho ilícito, el proyecto determina las diversas conductas que pueden acarrear una responsabilidad al Estado, como lo serían, en primera instancia, el comportamiento de sus órganos internos, ya sea ejecutivo, legislativo, judicial o de cualquier otra índole, independientemente de la organización interna del Estado, o de personas o entidades que ejerzan atribuciones del poder público, no importando la realización de actos ultra vires.

Respecto al elemento objetivo es claro el artículo 12 al establecer que hay violación de una obligación internacional cuando el hecho del Estado no está conforme a lo determinado por la obligación, cualquiera que sea su origen o naturaleza. Desde luego la obligación debe encontrarse vigente para el Estado infractor. Este capítulo, en fin, regula lo pertinente a la extensión en el tiempo de la obligación internacional, así como el caso de un hecho compuesto.

El capítulo cinco contempla las circunstancias que excluyen la ilicitud como serían el consentimiento, la legítima defensa, las contramedidas, la fuerza mayor, el peligro extremo, el estado de necesidad, y como 
estas causas no aplican en el supuesto relacionado al cumplimiento de normas imperativas.

Por otro lado, al hablar del contenido de la responsabilidad internacional del Estado, la segunda parte determina algunos principios generales, tales como:

- La continuidad del deber del Estado responsable de cumplir con la obligación violada.

- La obligación del Estado de poner fin al hecho ilícito y a ofrecer seguridades y garantías de que el acto u omisión no se repetirán.

- La obligación de reparar íntegramente el perjuicio causado por el hecho ilícito. Perjuicio que comprende tanto el daño material como el moral ocasionado a otro Estado. Como se podrá observar, aun cuando el daño no es un elemento del hecho ilícito si es importante para efectos de la reparación del daño.

- Al igual que el artículo 27 de la Convención de Viena sobre el Derecho de los Tratados de 1969, aquí el derecho interno es irrelevante como justificación del incumplimiento de la obligación.

- Algo que varía en esta parte es el hecho de que las obligaciones del Estado responsable pueden existir respecto de otro Estado, de varios Estados o de la comunidad internacional en su conjunto, dependiendo de la naturaleza y contenido de la obligación violada. Aquí entra un concepto tan vago como lo es el de "comunidad internacional en su conjunto" y lo que esto signifique.

- Las formas de reparación íntegra del perjuicio a través de la restitución, indemnización y satisfacción, de forma única o combinada.

- El pago de intereses sobre la suma principal adeudada y la contribución al perjuicio por parte del Estado lesionado para determinar la reparación.

El capítulo III de la segunda parte regula los aspectos relacionados con las violaciones graves de obligaciones emanadas de normas imperativas del derecho internacional general, según el cual los Estados deben cooperar para poner fin, siempre por medios lícitos, a las violaciones de este tipo; pero además los Estados se obligan, no sólo a no reconocer como lícita las situaciones generadas por este tipo de violaciones, sino a no prestar ayuda o asistencia para mantener dicha situación. Este capítulo 
establece además que el artículo 41 se entenderá "sin perjuicio de las demás consecuencias enunciadas en esta parte y de toda otra consecuencia que una violación a la que se aplique el presente capítulo pueda generar según el derecho internacional".

La tercera parte establece que el Estado lesionado tiene derecho a invocar la responsabilidad de otro Estado cuando sea directamente afectado por la violación de la obligación, en cualquier forma en que esto pueda darse. Sin embargo, aquí se agrega el hecho de que se considerará Estado lesionado si la obligación violada existe con relación a la comunidad internacional en su conjunto y la violación de la obligación "es de tal índole que modifica radicalmente la situación de todos los demás Estados con los que existe esa obligación con respecto al ulterior cumplimiento de ésta". 6

Esta tercera parte determina una especie de procedimiento para que proceda la reclamación por parte del Estado lesionado, que iniciaría con la notificación al Estado responsable, las circunstancias bajo las cuales dicha responsabilidad no podrá ser invocada, la renuncia del derecho a invocar la responsabilidad, así como la existencia de una pluralidad de estados lesionados o de estados responsables.

Un artículo interesante es el 48, el que comentaremos en el apartado subsecuente.

El capítulo II de la tercera parte hace referencia a las contramedidas como forma de inducir al Estado infractor a cumplir con sus obligaciones, medidas que se limitarán al incumplimiento temporario de obligaciones internacionales entre ambos Estados y que deberán ser tomadas en forma que permitan la reanudación del cumplimiento de las citadas obligaciones, además de ser proporcionales al perjuicio sufrido.

El artículo 50 enumera las obligaciones que no pueden ser afectadas por las contramedidas como las relativas: a la abstención de recurrir a la amenaza o al uso de la fuerza enunciada en la Carta de San Francisco; las establecidas para protección de los derechos humanos fundamentales; las de carácter humanitario que prohíben las represalias, y cualquier otra emanada de normas imperativas.

Este mismo capítulo determina las condiciones que debe cumplir el Estado lesionado para poder recurrir a las contramedidas. 
La cuarta y última parte alude a disposiciones generales tales como la lex specialis, la responsabilidad de las organizaciones internacionales o de los individuos, y finalmente el reconocimiento de la Carta de las Naciones Unidas.

\section{LOS ARTÍ́CULOS OBJETO DE DEBATE}

Son varias las disposiciones que llaman la atención de la doctrina internacional, así como de los Estados, en cuanto a que resultan no sólo una codificación de la práctica internacional, sino también implicarían normas generadas del desarrollo progresivo del derecho internacional, actividad que es facultad de la Comisión de Derecho Internacional; sin embargo, el resultado corresponde ser aprobado por los Estados. Aunque el proyecto contiene diversas disposiciones que merecerían ser objeto de comentario, en este apartado, únicamente haremos referencia al daño, a las violaciones graves de obligaciones derivadas de normas imperativas de derecho internacional general, así como los artículos relativos a la invocación de la responsabilidad.

\section{1. ¿El daño, elemento del hecho internacionalmente ilícito?}

El artículo 2 del proyecto al señalar los elementos del hecho ilícito hace referencia a la imputación al Estado de una acción u omisión que sea violatoria de una obligación internacional que se encuentre en vigor para el Estado infractor, sin embargo, el daño, considerado por un amplio sector de la doctrina como elemento necesario, no fue contemplado en el proyecto en cuestión, situación que obedeció a la concepción de Roberto Ago, relator especial en el momento en que fue aprobada la primera parte del proyecto en primera lectura.

En el 22a. periodo de sesiones de la Comisión de Derecho Internacional en 1970, en un cuestionario preparado por Roberto Ago, relator especial, en relación con su segundo reporte sobre el tema de la responsabilidad internacional del Estado, exponía la cuestión, a manera de pregunta, de si el daño debía ser tomado en cuenta como un tercer elemento del hecho ilícito internacional. ${ }^{7}$

7 Yearbook of the International Law Commission 1970, vol. I: Summary records of the twenty-second session, 4 may-10 july 1970, New York, United Nations, p. 175. 
En el 25o. periodo de sesiones de la Comisión de Derecho Internacional, que se llevó a cabo en 1973, Roberto Ago explicaba que cuando se habla del daño en el derecho internacional, se está haciendo referencia al daño en el derecho civil, es decir a un perjuicio económico.

Los términos "préjudice" (francés) e "injury" (inglés) designan la lesión naturalmente causada por una acción que constituye incumplimiento de una obligación internacional, pero no es necesariamente un daño en el sentido económico que generalmente se da a esa palabra. Además, el hecho de que algunos autores estimen al daño como un tercer elemento, se debe fundamentalmente, a que han considerado la figura de la responsabilidad desde el punto de vista exclusivo de los daños ocasionados a los extranjeros, es decir, en un marco en el que la obligación internacional infringida determina el no causar o prevenir el daño; sin embargo, existen ejemplos que demuestran la existencia de un hecho ilícito internacional sin que haya daño, como es el supuesto del Estado que no adopta la legislación a que se ha obligado en un tratado internacional, con lo cual, en estricto sentido, no causa daño a los otros a pesar del incumplimiento. ${ }^{8}$

En razón de lo anterior, Ago afirma que:

En consecuencia, no puede decirse que el elemento denominado del "daño" sea la tercera condición de existencia de un hecho internacionalmente ilícito, ya que hay hechos internacionalmente ilícitos que no acarrean daños económicos $\mathrm{y}$, si bien es cierto que todo incumplimiento de una obligación implica un perjuicio, el elemento de perjuicio está ya comprendido en el incumplimiento de la obligación. ${ }^{9}$

El señor Yasseen explicó su conformidad con el relator especial, de la siguiente manera:

En cuanto al daño, es difícil concebir que pueda haber responsabilidad en ausencia de todo daño. La máxima "no hay acción sin interés" parece tan válida en el derecho internacional como en el derecho interno. El daño o perjuicio podría caracterizarse por la lesión de un derecho. Pero, como ha

8 Anuario de la Comisión de Derecho Internacional 1973, vol. I: Actas resumidas del vigésimo quinto periodo de sesiones, 7 de mayo-13 de julio de 1973, Nueva York, Naciones Unidas, 1974, p. 20. y 178.

9 Anuario de la Comisión...1973, cit., p. 20. Además véase Yearbook...1970, cit., pp. 175 
dicho el Relator Especial, todo incumplimiento de una obligación internacional implica la lesión de un derecho subjetivo. Por consiguiente, el concepto de daño o de perjuicio está implícitamente contenido en el de incumplimiento de una obligación, aunque, por supuesto, no se trata necesariamente de un daño material. En consecuencia, no es preciso mencionar el daño separadamente, como tercer elemento constitutivo de un hecho internacionalmente ilícito. ${ }^{10}$

Por el contrario, otros miembros de la comisión no estuvieron de acuerdo en excluir la figura del daño de los elementos del hecho ilícito internacional; por ejemplo, el señor Sette Câmara opinaba que la posición del relator especial acerca de dicha figura, únicamente se basaba en el daño patrimonial, cuando existen una diversidad de daños, que van más allá de las pérdidas materiales de los particulares, daños que son sufridos por el Estado y no por los particulares, como sería el caso de un oficial de aduanas que abre una valija diplomática, aún cuando ésta no contenga documentos o materiales confidenciales, no hay un daño material directo, pero si existe un daño moral a la dignidad del Estado. Al efecto, afirmaba que "el elemento de daño es siempre el que autoriza a un Estado a formular una reclamación contra otro y a pedir reparación". ${ }^{11}$

Finalmente, en el informe de la Comisión de Derecho Internacional en su 530. periodo de sesiones de 2001, en los comentarios al artículo 2 del proyecto se afirma que:

La exigencia de elementos de ese tipo depende del contenido de la obligación primaria, y no existe ninguna regla general al respecto. Por ejemplo, la obligación que incumbe en virtud de un tratado de promulgar una legislación uniforme es violada por el hecho de no promulgar la ley, y no es necesario que otro Estado Parte indique que ha sufrido un daño concreto debido a ese incumplimiento. Que una obligación determinada no se cumpla por la mera inacción del Estado responsable, o que se exija que se produzca alguna otra circunstancia dependerá del contenido y la interpretación de la obligación primaria y no puede determinarse en abstracto. ${ }^{12}$

10 Anuario de la Comisión...1973, cit., p. 25.

11 Anuario de la Comisión...1973, cit., p. 23.

12 Informe de la Comisión de Derecho Internacional. 53o. periodo de sesiones (23 de abril a 1o. de junio y 2 de julio a 10 de agosto de 2001). Asamblea General. Documentos oficiales 56o. periodo de sesiones. Suplemento No. 10 (A/56/10), p. 44. 
Por otro lado, James Crawford señalaba que existe realmente un problema al tratar de aclarar los conceptos de "injury" y "dammage" por las diferentes connotaciones que dichos términos encierran no sólo en inglés sino en las diversas tradiciones jurídicas, por lo que la comisión había decidido utilizar "injury" el cual comprendía "any dammage" ya fuera material o moral originado por el hecho internacionalmente ilícito del Estado. ${ }^{13}$

En pocas palabras, el proyecto elude estas cuestiones bajo el argumento de que los problemas del daño serán determinados por las normas primarias y que, únicamente, corresponde al proyecto, como norma secundaria que es, establecer si una obligación ha sido violada y a quién corresponde atribuir la responsabilidad; ${ }^{14}$ sin embargo, la regla general determina que únicamente el Estado dañado puede invocar la responsabilidad del Estado infractor.

Como bien menciona Eric Wyler la desaparición del daño como elemento del hecho internacionalmente ilícito considerado como una revolución conceptual puede sorprender, sobre todo cuando dicho elemento se encuentra presente en la segunda parte del proyecto y es requisito indispensable para invocar la responsabilidad. ${ }^{15}$

\section{Violaciones graves de obligaciones derivadas de normas imperativas de derecho internacional general en lugar de crímenes internacionales}

Algo que por mucho tiempo caracterizó el proyecto sobre la responsabilidad del Estado fue la inclusión de los crímenes internacionales en el famoso artículo 19,16 que de acuerdo con Roberto Ago era la forma de

13 Crawford, James et al., "The ILC's Articles on Responsibility of States for Internationally Wrongful Acts: Completion of the Second Reading”, en European Journal of International Law, vol. 12, Issue 5, 2001, p. 972.

14 Véase al efecto los comentarios de Bodansky, Daniel y Crook, John R, "Symposium: The ILC'S State Responsibility Articles. Introduction and Overview", American Journal of International Law, Washington, vol. 96, núm 4, October 2002, p. 781.

15 Wyler, Eric, 'From 'State Crime' to Responsibility for 'Serious Breaches of Obligations under Peremptory Norms of General International Law", European Journal of International Law, núm. 13, 2002, p. 1152.

16 El artículo en cuestión dice: Crímenes y delitos internacionales: 1. El hecho del un Estado que constituye una violación de una obligación internacional es un hecho internacional ilícito sea cual fuere el objeto de la obligación internacional violada. 2. El hecho internacionalmente ilícito resultante de una violación por un Estado de una obligación internacional tan esencial para la salvaguardia de intereses fundamentales de la comunidad internacional que su violación está 
distinguir las obligaciones internacionales violadas en función de su gravedad. Artículo que sobrevivió aproximadamente 20 años y que fue motivo de discusión no solamente de la doctrina sino de una gran parte de los Estados, quienes consideraban que el precepto no reflejaba la práctica de los propios Estados.

No cabe la menor duda acerca de la gran influencia que tuvo en las ideas de Roberto Ago, primeramente el artículo 53 de la Convención de Viena sobre el Derecho de los Tratados de 1969, que no sólo define a las normas imperativas de derecho internacional general sino que la establece como causa de nulidad del tratado; así como el obiter dictum de la Corte Internacional de Justicia en la sentencia del caso Barcelona Traction, Light and Power Company, Limited del 5 de febrero de 1970, en el que se distinguen las obligaciones internacionales y se reconoce la existencia de obligaciones hacia la comunidad internacional en su conjunto.

No obstante lo anterior, basta revisar la opinión de los Estados acerca del artículo 19 para darse cuenta de un rotundo y casi unánime rechazo del mismo, bajo el argumento de que el derecho internacional consuetudinario aunque reconoce la responsabilidad penal de los individuos, nunca ha reconocido la responsabilidad penal de los Estados bajo la máxima societas delinquere non potest. ${ }^{17}$

Ciertamente, Ago tenía razón en el hecho de que había que distinguir que no todas las obligaciones internacionales son iguales y que no es po-

reconocida como crimen por esa comunidad en su constituye un crimen internacional. 3. Sin perjuicio de las disposiciones del párrafo $2 \mathrm{y}$ de conformidad con las normas de derecho internacional en vigor, un crimen internacional puede resultar, en particular: a) De una violación grave de una obligación internacional de importancia esencial para el mantenimiento de la paz y la seguridad internacionales, como la que prohíbe la agresión; b) De una violación grave de una obligación internacional de importancia esencial para la salvaguardia del derecho a la libre determinación de los pueblos, como la que prohíbe el establecimiento o mantenimiento por la fuerza de una dominación colonial; c) De una violación grave y en gran escala de una obligación internacional de importancia para la salvaguardia del ser humano, como las que prohíben la esclavitud, el genocidio, el apartheid; d) De una violación grave de una obligación internacional de importancia esencial para la salvaguardia y protección del medio humano, como las que prohíben la contaminación masiva de la atmósfera o de los mares. 4. Todo hecho internacionalmente ilícito que no sea un crimen internacional conforme al párrafo 2 constituye un delito internacional.

17 De acuerdo con algunos de los miembros de la Comisión de Derecho Internacional, la responsabilidad internacional del Estado no es civil ni penal, simplemente internacional. Véase State Responsibility. Comments and observations received from Governments. International Law Commission, 50o. session (Geneva 20 may-12 jun 1998; New York 27 july-14 august 1998) A/CN.4/488, Assembly General, United Nations, 1998, pp. 51 y ss.; Tams, Christian J., "Do Serious Breaches give rise to any Specific Obligations of the Responsible State?", European Journal of International Law, núm. 13, 2002, p. 1167. 
sible equiparar la violación de un tratado bilateral con la violación de la norma que prohíbe la agresión o el genocidio; como resultado debían darse diferentes consecuencias, mismas que no se reflejaron en el proyecto de $1996 .{ }^{18}$ Realmente era muy difícil pensar en un tipo de responsabilidad penal del Estado, idea que va asociada con la característica de centralización que se goza al interior del Estado, pero no al exterior que es totalmente descentralizado, pero tampoco podía excluirse la idea de una distinción entre obligaciones que tanto la comunidad como los tribunales internacionales han plenamente reconocido.

De ahí que James Crawford, el quinto y último relator especial, consideró pertinente dar un nuevo giro al proyecto, tratando de conciliar las posturas más controvertidas, esto es desaparecer el artículo 19, pero reconociendo la existencia de violaciones graves de normas imperativas de derecho internacional general, lo que podemos observar en los artículos 40 y 41 del proyecto de 2001. ${ }^{19}$ Sin embargo, para algunos estudiosos existe identidad entre el crimen internacional y la violación grave de obligaciones derivadas de normas imperativas de derecho internacional general, ${ }^{20}$ situación que también podemos observar en las consecuencias que fueron establecidas para los crímenes en el artículo 53 del proyecto de 1996, muy similares a las consecuencias de las violaciones graves establecidas en el artículo 41 del proyecto de $2001 .^{21}$

Como bien señala el profesor Giuseppe Palmisano, todos los hechos ilícitos no son de la misma gravedad. Para defenderse de las conductas antisociales de sus integrantes, las sociedades disponen de un sistema jurídico, de tal suerte que a la diferente nocividad de las infracciones corresponde un grado diferente de ilegalidad, cuya medida es dada por el

18 Véase los comentarios del Relator Ago al respecto en Anuario de la Comisión de Derecho Internacional 1976, vol. I: Actas resumidas del vigésimo octavo periodo de sesiones, 3 de mayo-23 de julio de 1976, Nueva York, Naciones Unidas, 1976, p. 63.

19 Véase al efecto los comentarios del relator especial James Crawford en la publicación Crawford, James et al., op. cit., pp. 977 y ss.

20 Dupuy, Pierre Marie, "A General Stocktaking of the Connections between the Multilateral Dimension of Obligations and Codification of the Law of Responsibility", European Journal of International Law, vol. 13, núm. 5, noviembre de 2002, p. 1061.

21 Véase el artículo 53 del proyecto de 1996 en el que se puede observar que existía la misma obligación para todos los Estados de no reconocimiento de la legalidad de la situación creada por el crimen, no prestar ayuda ni asistencia al Estado infractor para mantener la situación creada por el crimen, así como el deber de cooperación en la aplicación de medidas destinadas a eliminar las consecuencias del crimen. Informe de la Comisión de Derecho Internacional sobre la labor realizada en su 480. periodo de sesiones. A/51/332, 30 de julio de 1996, Nueva York, Asamblea General de Naciones Unidas, p. 36. 
rigor de las consecuencias previstas por el sistema para cada una de las infracciones. ${ }^{22}$

Por su parte, el artículo $40^{23}$ sólo contempla la violación agravada de obligaciones derivadas de normas de ius cogens, ¿esto querría decir que si no es grave la violación se aplican las consecuencias de cualquier otra obligación internacional?

Para el proyecto el término "grave" implica un incumplimiento flagrante o sistemático de la obligación por el Estado responsable. En los comentarios del artículo 40 se indica lo siguiente:

La palabra "grave" significa que se precisa una cierta magnitud de violación para no trivializarla y no quiere sugerir que alguna violación de esas obligaciones no sea grave, o sea de algún modo excusable. Pero cabe imaginar casos relativamente menos graves de violación de normas imperativas y por ello es preciso limitar el alcance de este capítulo a las violaciones más graves o sistemáticas. ${ }^{24}$

De acuerdo con esto, debemos entender que la violación de obligaciones internacionales derivadas de normas de ius cogens que no puedan ser calificadas como graves tendrían las mismas consecuencias de cualesquier otra violación. Según los comentarios contenidos en el proyecto, la violación será considerada sistemática cuando se realice de manera organizada y deliberada, mientras que por "flagrante" se entiende la intensidad de la violación o de sus efectos: responden a este tipo, un ataque directo y abierto contra los valores que protege la norma. ${ }^{25}$

Las consecuencias establecidas en el proyecto para las violaciones graves de obligaciones derivadas de normas de ius cogens, se encuentran determinadas en el artículo 41, en que se regula el deber de los Estados de cooperar para poner fin, por medios lícitos, a toda violación grave y el no reconocimiento como lícita de las situaciones creadas por dicha violación. La diferencia con cualesquier otra violación estaría en el hecho de

22 Palmisano, Giuseppe, "Les causes d'agravation de la responsabilité des états et la distinction entre 'crimes' et 'delits internationaux", Revue Générale de Droit International Public, París, Pedone, t. 98/1994/3, 1994, pp. 630 y 631.

23 El precepto dice: "1. El presente capítulo se aplicará a la responsabilidad internacional generada por una violación grave por el Estado de una obligación que emane de una norma imperativa del derecho internacional general. 2. La violación de tal obligación es grave si implica el incumplimiento flagrante o sistemático de la obligación por el Estado responsable".

24 Informe de la Comisión de Derecho Internacional. 53o. periodo de sesiones, cit., p. 308.

25 Idem. 
que en el caso de violaciones graves se impone el deber a los Estados de no reconocimiento y tratar de poner fin al hecho. ¿Es posible pensar en otro tipo de consecuencias? Realmente no. Las características actuales del derecho internacional no permiten otra cosa, es decir la creación de un órgano centralizado encargado de determinar la responsabilidad y, en todo caso, de aplicar sanciones por el incumplimiento. De ahí que el proyecto, aunque parezca muy pobre en ese sentido, no ha hecho más que reflejar una realidad internacional.

\section{3. ¿Quiénes se encuentran facultados para hacer valer la responsabilidad internacional?}

Otra de las innovaciones del proyecto consiste en determinar quiénes están facultados para invocar la responsabilidad del Estado. En primer lugar, la tiene el Estado lesionado, lo que no es nada nuevo. En segundo lugar, es que se considerará Estado lesionado y como tal tiene la capacidad de invocar la responsabilidad, si la obligación violada existe con relación a la comunidad internacional en su conjunto y la violación de la obligación "es de tal índole que modifica radicalmente la situación de todos los demás Estados con los que existe esa obligación con respecto al ulterior cumplimiento de ésta" (artículo 42, b), ii). En tercer lugar, y aquí viene lo novedoso, se regula en el artículo 48 la invocación de la responsabilidad por un Estado distinto del Estado lesionado cuando la obligación violada existe con relación a la comunidad internacional en su conjunto (artículo 48, 1, b).

De acuerdo con los comentarios del proyecto de 2001, un Estado lesionado en el sentido del artículo 42 tiene derecho a recurrir a todos los medios de reparación previstos en los artículos. En el caso del artículo 42, b), ii), señala la comisión que se trata de obligaciones dimanentes del derecho internacional cualquiera que sea su fuente y que afectan directamente a un número importante de Estados.

Por otro lado, la situación de un Estado lesionado debe distinguirse de la de cualquier otro Estado que pueda tener derecho a invocar la responsabilidad, por ejemplo, con arreglo al artículo 48 que se refiere al derecho a invocar la responsabilidad en relación con un interés general compartido. ${ }^{26}$ 
La segunda parte de esta disposición alude a las obligaciones erga omnes reconocidas por la Corte Internacional de Justicia en el caso Barcelona Traction, y que la Comisión de Derecho Internacional quiso poner en práctica al regularla, argumentando que dicho precepto "se basa en la idea de que en los casos de violación de obligaciones específicas que protegen los intereses colectivos de un grupo de Estados (erga omnes partes) o los intereses de la comunidad internacional en su conjunto, pueden invocar la responsabilidad Estados que no son Estados lesionados (erga omnes) en el sentido del artículo 42". ${ }^{27}$

Cabe recordar que en este punto, aun cuando la Corte Internacional de Justicia en el caso Barcelona Traction hizo una distinción entre obligaciones y confirmó la existencia de las obligaciones erga omnes; el mismo tribunal, muy pocos años antes, en el caso del sudoeste africano determinó que en el derecho internacional vigente no se daba la actio popularis que facultaría a los Estados no afectados directamente en su derecho a invocar la responsabilidad, ${ }^{28}$ situación que confirmó algunos años después en el caso de Timor Oriental. ${ }^{29}$

Señala el profesor Dupuy que la percepción del cuarto relator especial, Willem Riphagen, al distinguir entre Estados directa e indirectamente dañados, tuvo el mérito de reconocer que todos los Estados podían ser afectados aunque en diferente medida. Es sabido que ningún Estado se atrevería a invocar la responsabilidad si no ha sufrido directamente una lesión a sus derechos; sin embargo, la consideración de que todos los Estados pueden ser dañados va en función de que sus derechos subjetivos han sido afectados y tienen el interés legal en que se respeten. En el primer caso el Estado ha sido dañado en sus derechos subjetivos, mientras que en el segundo, hablamos de Estados dañados en sus intereses objetivos, es decir, estos se encuentran particularmente interesados en el respeto a la legalidad establecida en las distintas normas internacionales. ${ }^{30}$

No obstante lo anterior, sigue explicando Dupuy:

27 Informe de la Comisión de Derecho Internacional. 53o. periodo de sesiones, cit., pp. 349, 352 y ss.

28 Fallo del 18 de julio de 1966 sobre los Casos Relativos al África Sudoccidental (segunda fase).

29 Sentencia del 30 de junio de 1995, Affaire relative au Timor Oriental (Portugal c Australie), Cour Internationale de Justice, année 1995.

30 Dupuy, Pierre Marie, op. cit., pp. 1071. 
In particular, we do not know whether the right of all states to invoke responsibility against a perpetrator state is concerned only with the fact that the obligation ignored was erga omnes, or whether in the ILC's conception the generality of this right to action presupposes that the obligation erga omnes in question also has a peremptory nature; this is the case, for instance, for the ban on torture, according to the judgment on the International Criminal Tribunal for the former Yugoslavia in the Furundzija case. $^{31}$

Como podemos observar, a pesar de las buenas intenciones de la Comisión de Derecho Internacional de querer regular situaciones que ya han sido reconocidas, por lo menos por los tribunales internacionales, el artículo 48 aún genera demasiadas controversias por los conceptos que comprende, fundamentalmente el aspecto de las obligaciones erga omnes, y sí existiría una relación con las normas imperativas de derecho internacional general comprendidas en los artículos 40 y 41. Sin embargo, es de considerarse la existencia de un gran avance en esta materia, situación que no era posible pensar por lo menos hace sesenta años, y que implica un gran comienzo en caso de ser aprobado el proyecto en cuestión, reglamentación que podrá ir mejorando con el devenir de los años y cuando la práctica, no sólo de los Estados sino de los tribunales internacionales, se vaya consolidando.

Otro problema que nos encontramos es cuando el derecho conferido en este artículo pueda ser utilizado para justificar intervenciones unilaterales bajo el argumento de que ha sido vulnerada una obligación debida a la comunidad internacional en su conjunto. ${ }^{32}$

\section{CONCLUSIONES}

En términos generales, el Proyecto sobre la Responsabilidad Internacional del Estado por hecho internacionalmente ilícito es un excelente intento de codificación. Es un proyecto que cuenta con más de cuarenta años de trabajo de la Comisión de Derecho Internacional, trabajo de pri-

31 Dupuy, op. cit., pp. 1074 y 1075.

32 Véase además los comentarios de Brown Weiss, Edith, "Invoking State Responsibility in the Twenty-first Century", American Journal of International Law, Washington, vol. 96, núm. 4, October 2002, p. 805. 
mer nivel en el que participaron grandes juristas iuspublicistas, tratando de conciliar las diversas posturas de la doctrina y la práctica.

No obstante lo anterior, el problema de los artículos está, no tanto en los relacionados con la codificación del tema, sino en aquellos otros de desarrollo progresivo que generan escozor entre los Estados, como es el caso de las violaciones graves de obligaciones derivadas de normas imperativas de derecho internacional general, así como la facultad de los Estados no lesionados para hacer valer la responsabilidad por la violación de obligaciones erga omnes, y la poca claridad que existe en determinar la relación entre estos dos aspectos contenidos en los artículos 40 y 41 con el 48.

Por otro lado, no se ve claro que el documento pueda ser sancionado a corto plazo, aunque sería deseable que se aprobara bajo la forma de un tratado multilateral y, en consecuencia, como fuente del derecho internacional, en la norma jurídica aplicable en tema tan controversial.

Ciertamente existe demasiada crítica en contra del proyecto, por parte de los Estados y la doctrina; sin embargo, aquel refleja parte de la realidad internacional determinada no sólo por la práctica de los Estados, sino por las decisiones de los tribunales internacionales, encargados de dictar el derecho, citados en los comentarios anexos al proyecto, por lo que siempre será preferible su aprobación y aplicación a que quede en letra muerta como un trabajo que fue superior a la Comisión de Derecho Internacional.

\section{BIBLIOGRAFÍA}

Anuario de la Comisión de Derecho Internacional 1973, vol. I: Actas resumidas del vigésimo quinto periodo de sesiones, 7 de mayo-13 de julio de 1973, Nueva York, Naciones Unidas, 1974.

Anuario de la Comisión de Derecho Internacional 1976, vol. I: Actas resumidas del vigésimo octavo periodo de sesiones, 3 de mayo-23 de julio de 1976, Nueva York, Naciones Unidas, 1976.

Bederman, David J., "Counterintuiting Countermeasures", American Journal of International Law, Washington, vol. 96, núm. 4, octubre de 2002.

BODANSKY, Daniel y CROOK, John R., "Symposium: The ILC'S State Responsability Articles. Introduction and Overview", American 
Journal of International Law, Washington, vol. 96, núm. 4, octubre de 2002.

BROWN WeISS, Edith, "Invoking State Responsability in the Twentyfirst Century", American Journal of International Law, Washington, vol. 96, núm. 4, octubre de 2002.

Crawford, James; PeEl, Jacqueline y Olleson, Simon, “The ILC's Articles on Responsability of States for Interantionally Wrongful Acts: Completion of the Second Reading", European Journal of International Law, vol. 12, Issue 5, 2001.

DUPUY, Pierre Marie, "A General Stocktaking of the Connections between the Multilateral Dimension of Obligations and Codification of the Law of Responsibility", European Journal of International Law, vol. 13, núm. 5 , noviembre de 2002.

Hart, H. L. A., The Concept of Law, 2a. ed., Clarendon Press, Oxford, Great Britain, 1997.

Informe de la Comisión de Derecho Internacional sobre la labor realizada en su 480. periodo de sesiones. A/51/332, 30 de julio de 1996, Nueva Cork, Asamblea General de Naciones Unidas.

Informe de la Comisión de Derecho Internacional. 53o. periodo de sesiones (23 de abril a 1o. de junio y 2 de julio a 10 de agosto de 2001). Asamblea General. Documentos Oficiales 56o. periodo de sesiones. Suplemento núm. 10 (A/56/10).

NolTE, George, "From Dionisio Anzilotti to Roberto Ago: The Classical International Law of State Responsibility and the Traditional Primacy of a Bilateral Conception of Inter-state Relations", European Journal of International Law, núm. 13, 2002.

PALMISANO, Giuseppe, "Les causes d'agravation de la responsabilité des états et la distinction entre 'crimes' et 'delits' internationaux", Revue Générale de Droit International Public, París, Pedone, 1994, tome 98/1994/3.

SPINEDI, Marina, "From one Codification to another: Bilateralism and Multilateralism in the Genesis of the Codification of the Law of Treaties and the Law of State Responsibility", European Journal of International Law, núm. 13, 2002.

State Responsibility, Comments and Observations received from Governments. International Law Commission, 50o. session (Geneva 20 may-12 june 1998; New York 27 july-14 august 1998) A/CN.4/488, Asamblea General, United Nations, 1998. 
TAMS, Christian J., "Do Serious Breaches give rise to any Specific Obligations of the Responsible State?, European Journal of International Law, núm. 13, 2002.

WYLER, Eric, From "State Crime" to Responsibility for "Serious Breaches of Obligations under Peremptory Norms of General International Law", European Journal of International Law, núm. 13, 2002.

Yearbook of the International Law Commission 1970, vol. I: Summary records of the twenty-second session, 4 may-10 july 1970, United Nations, New York. 